\title{
Analysis of Preventive and Health Promotion Program Using IPO Model in Primary Health Care in Semarang
}

\author{
$1^{\text {st }}$ Prasetijono \\ Medical Faculty \\ Universitas Islam Sultan Agung \\ Semarang, Indonesia \\ purwitofis@gmail.com
}

\author{
$2^{\text {nd }}$ Citaprasetya \\ Public Health Faculty \\ Universitas Indonesia \\ Depok, Indonesia \\ avida.prasetya@gmail.com
}

\author{
$3^{\text {rd }}$ Yuliyanti \\ Medical Faculty \\ Universitas Islam Sultan Agung \\ Semarang, Indonesia \\ purwitofis@gmail.com
}

\begin{abstract}
Primary Health Care (PHC) has a strategic role to develop and maintain prevention and health promotion programs. This paper researched was done in PHC in Semarang, by evaluating the indicators in InputProcess-Output (IPO) Model. The supporting factors for health promotions are availability of funds and facilities and infrastructure in PHC. The inhibiting factor is the lack of health promotion knowledge and the management of PHC. Even so, the planning of health promotion program was done by PHC.
\end{abstract} health

Keywords- PHC, health promotion, IPO Model, public

\section{INTRODUCTION}

Public Health Efforts are any activities to maintain and improve health (Promotional Efforts), and prevent and overcome with the emergence of health problems with families, groups, and communities as target. Promotional and prevention efforts are key to achieve the goal of health paradigm, as to improve health status and control of health costs. This effort is a strategic step in improving health status, which leads to health cost control including the current era of JKN (Jaminan Kesehatan Nasional) and sustainability in the next year, so as to achieve Universal Health Coverage (UHC) in 2019 [3].

SKRT and Riskesdas data shows that there has been an epidemiological transition of diseases in Indonesia from infectious diseases to non-communicable diseases that require special treatment for long periods of time and even lifetime, resulting in high health costs. Prevention of noncommunicable diseases should be undertaken to control future health costs, so that prevention and health promotion aspects must exist in the process of providing health services as stated in Presidential Decree No.12 of 2013

Primary Health Care (PHC) has a strategic role in prevention and health promotion programs. The obstacles in implementing prevention and health promotion programs are the lack of quality and quantity of human resources, facilities and infrastructure in PHC; patient attitudes and also patient compliance on treatment. The quality of human resources must be improved by the knowledge of extension methods and health education materials. Organizational development strategy is also an essential factor in the implementation of prevention and health promotion programs. Some of those circumstances affect the prevention and health promotion activities to be implemented not optimally in PHC, with that result, further research on the factors that support and inhibit the implementation of prevention and health promotion activities in PHC need to be done [4,5,7].

This study aims to determine the factors supporting and inhibiting the implementation of preventive and health promotion activities in PHC in Semarang.

\section{MATERIALS AND METHOD}

Study is observational research by cross sectional design, done to all person in charge or doctor in PHC who's willing to be respondent, and served in PHC in cooperation with BPJS (Social Security Administrator of Health). Samples were taken by consecutive sampling technique. The research instrument was questionnaire and interview guide which contains input and process evaluation along with check list of observation to be filled by enumerator. Data collection was done by enumerators who have been trained on how to collect data in this research.

The analysis of this research was using Input-ProcessOutput (IPO) Models, introduce by Donabedian. The Input had human sources, service delivery costs, policies and guidelines for the implementation of activities and materials/tools for data collection and processing. While The Process was about program planning in some period of time, including targeting, budgeting and responsible activities, program implementation progress and the supervision or assessment of the program, The Output was the program performance.

Good inputs allow good processes, good processes allow good output, and good output will have an impact on good outcomes, so good input becomes the basis for 
quality activities, good processes are the basis for quality output, with output quality the basis for the expected impact on the target. One method of evaluating the health service program is by continually observing the program to interpret the information obtained, and formulating the program feedback on the relevance and efficiency of the program so as to provide a better impact for the continuity of the program according to the principle of management.

Hence, this research evaluated the model's component, The Input data was collected by questionnaire, The Process data was collected by PHC Report, and since The Output is the result of the program implementation or management working result and not all PHC made the report, the researcher couldn't analyze The Output phase.

Analysis was done descriptively using frequency for respondent characteristics, meanwhile for input and process components are reported qualitatively.

The data obtained in this research is then in the entry and the coding, then analyzed the descriptive frequency to identify the characteristics of respondents, then determine the factors - factors supporting and inhibitors most experienced by FKTP. Then to determine which factors are most influential, analyzed the relationship by using logistic regression.

\section{RESULTS AND DISCUSSION}

This study researched on 46 respondents, while 2 respondents didn't give complete answered questionnaire, this study only analyze 44 respondents. The characteristics of 44 respondents were shown by the table.

\section{TABLE 1. RESPONDENT CHARACTERISTICS}

\begin{tabular}{|c|c|}
\hline Respondent Characteristics & Count (\%) \\
\hline \multicolumn{2}{|l|}{ Age } \\
\hline $20-29$ y.o. & 15,9 \\
\hline $30-39$ y.o. & 40,9 \\
\hline $40-49$ y.o. & 11,4 \\
\hline$>50$ y.o. & 29,5 \\
\hline \multicolumn{2}{|l|}{ Gender } \\
\hline Female & 63,6 \\
\hline Male & 36,4 \\
\hline \multicolumn{2}{|c|}{ Education } \\
\hline Undergraduate & 88,6 \\
\hline Post-Graduate & 11,5 \\
\hline \multicolumn{2}{|c|}{ Employment status } \\
\hline Permanent & 84,1 \\
\hline Temporary & 13,6 \\
\hline \multicolumn{2}{|c|}{ Length of Work } \\
\hline$<1$ year & 11,4 \\
\hline $1-3$ years & 20,5 \\
\hline $4-6$ years & 25 \\
\hline $7-9$ years & 15,9 \\
\hline $10-13$ years & 9,1 \\
\hline$>14$ years & 18,2 \\
\hline
\end{tabular}

Based on the respondent characteristics, most of them are at 30-39 y.o, which means that the respondents were in productive age and most of them were permanent employees. We can say that they already had experience in their job because more than $60 \%$ were experienced for more than 3 years. The respondents are graduates of medical, dentistry, medical profession programs and dental profession programs, based on that education background, the respondents must have comprehended the preventive and health promotion activities. While the dentists should comprehend the oral and dental health of the Society, the doctors' competence standard is the patient management of holistic and comprehensive, including conducting health promotion for individual family and society [3].

\section{A. The Input:}

The respondents were asked about the definition of Health Promotion, it is found that only $13.6 \%$ answered correctly. It is fact that most of them didn't really understand the definition of health promotion. According to WHO, health promotion should include strengthening health, ability to control health issues, reducing the health impacts caused by the environment, whether social, political or economic, allocating resources for the prevention of health problems, the spiritual social dimension that affects health, ecological approaches and the introduction of the development of society to develop effective strategies in health promotion programs. Health promotion in the Health Ministry Decree was defined as an effort to improve the ability of the community through learning from, by, for and with community, so that they can help themselves, and develop community-based activities, in accordance with local social culture and supported by public health policy.

Even though we found only small number of respondents understood the definition of health promotion, most of them knew the purpose of health promotion and all respondents knew what health promotion tools were.

All respondents agreed that health promotion needed to be done in PHC; PHC must implement clean and healthy living or PHBS (Perilaku Hidup Bersih dan Sehat; health promotion is strategic program for PHC development; and PHC must create a conducive environment for patients, families, visitors, and communities surrounding, so that they would be willing and able to have clean and healthy living.

Some of the respondents believed that health promotion was responsibilities that belonged to health promoter or health promotion worker, not by them, even though most of them disagreed. This fact showed that most PIC in PHC, doctors and dentists already knew the function of health promotion and realized that everyone must do health promotion, not only by some group of people. They also realized that PHC as strategic health promotion media, must implement PHBS, by program and facility.

Most of the respondents agree that health promotion needs big fund to be done, but not really need to be done in special room in PHC. Most of them also believed that health promotion not really needed promotion instruments.

\section{B. The Process:}

Using data obtained from PHC, 54.5\% respondents stated making the planning before doing preventive and health promotion activities. The Planning included identification of problems and needs of citizens, priority 
issues and plan the plan of action to address health problems arising in the community. Only 8 respondents stated that they also used health data and did initial survey to define health problem and citizen needs.

Monitoring conducted by PHC may vary, including achievement of process indicators, outputs, and outcomes. The number of respondents that their working place did monitoring and evaluation of prevention and health promotion programs was $72.7 \%$. The process indicators used by health facilities for monitoring and evaluating the prevention and health promotion activities in this research were the number of attendance and the number of counseling successfully conducted by health facilities, Output indicator was posttest score and / or discussion of question and answer, after giving information to the community. Outcome indicators was the number of visits to the health facility and reports of morbidity. The simpler planning is done only by preparing the material, the person who will deliver the material, and place, as well as determining the schedule and the cost of the implementation of the course.

\section{CONCLUSION}

By this research, we found that:

1. Factors that support the implementation of preventive and health promotion activities are: the attitude of medical officers to health promotion in PHC, availability of funds, sara and adequate infrastructure for the implementation of preventive and health promotion activities

2. Factors that impede the implementation of preventive and health promotion activities are: The knowledge of medical officers on preventive and health promotion activities in PHC, which is limited to providing information on clean and healthy lifestyle. So that the components of atmosphere development, advocacy and empowerment has not been done by the first level health facilities.

It can be concluded that the planning of health promotion program in PHC was not done by people that understood the definition of health promotions. Even though they understood the function, the aim of health promotion, it was doubtful that they could define the activities of health promotion. While they believed that health promotion not really need special room and promotion instruments, they still believed that health promotion needed much money or big fund to be done. They also believed that the successful of PHBS implementation was by the reason of conducive environment in $\mathrm{PHC}$, which means infrastructure and facilities of PHC must be assured. Not all PHC made report of the result of the program implementation or management working result.

It is recommended to provide training on health promotion methods for Primary Health Care with materials including resource management and facilities at Primary Health Care for the implementation of preventive and health promotion activities as well as planning, implementation and monitoring and evaluation techniques. And the need for policies that regulate the implementation of prevention and health promotion activities in Primary Health Care. It is necessary to conduct research on implementation of prevention and health promotion activities guidance in Primary Health Care and research on the object of prevention and health promotion activities.

\section{REFERENCES}

[1] Ashcroft R, "Health promotion and primary health care: Examining the discourse", J. Soc Work Public Health, 2015;30(2):107-16.

[2] Costello M, Taylor J, O'Hara L, "Impact evaluation of a health promotion-focused organizational development strategy on a health service's capacity to deliver comprehensive primary health care", Aust J Prim Health, 2015:21:444-9.

[3] Health department of Semarang City, "Health profile of Semarang 2015", Health, editor, Semarang: Health department of Semarang City; 2015. p. 1-104.

[4] Khoirudin A, Mulawarman AJID, "Suspect findings of tuberculosis in primary health care of Kediri", Management sciences, 2012:02 Number 0(Revitalisasi):141-53.

[5] Khotimah K, Kurdi FN, "Analysis of competency and capability to health promotion workers in Palembang", Journal of Medical and Health, 2016;3(1):383-9.

[6] Doctor Council of Indonesia, "Basic competency for doctor in Indonesia", 2012. 1-90 p.

[7] Kumar S, Preetha G, "Health promotion: an effective tool for global health", Indian J Community Med [Internet]. 2012:37(1):5.

[8] Mahmud AJ, Olander E, Wallenberg L, Haglund BJA, "Health Promoting Settings in Primary Health Care - 'halsotorg': an Implementation Analysis", J. BMC Public Health, 2010:10:707.

[9] March I, It IF, To D, That R, Aren P, Mildon PB, et al, "Nursing your community garden", Stress Int J Biol Stress [Internet]. 2012:72(3):1-10

[10] Martinez C, Bacigalupe G, Cortada JM, Grandes G, Sanchez A, Pombo $\mathrm{H}$, et al, "The implementation of health promotion in primary and community care: a qualitative analysis of the 'prescribe vida saludable' strategy", J. BMC Fam Pract [Internet]. 2017:18(1):23.

[11] Maxey HL, Norwood CW, Weaver DL, "Primary care physician roles in health centers with oral health care units", J Am Board Fam Med. 2017:30(4):491-504.

[12] Moreno-Peral P, Conejo-Cerón S, Fernández A, Berenguera A, Martínez-Andrés M, Pons-Vigués M, et al, "Primary care patients' perspectives of barriers and enablers of primary prevention and health promotion - a meta-ethnographic synthesis", J. PLoS One.2015:10(5):e0125004

[13] Rock C, Diehm C, Schneider S, "Physical Activity Promotion in Primary Health Care: Results from a German Physician Survey", Eur J Gen Pract [Internet]. 2012:18(2):86-91. 